\title{
Microglia Priming with Aging and Stress
}

\author{
Anzela Niraula ${ }^{1,2}$, John F Sheridan ${ }^{2,3}$ and Jonathan P Godbout ${ }^{\star, 1,2,4}$ \\ ${ }^{1}$ Department of Neuroscience, The Ohio State University, Columbus, OH, USA; ${ }^{2}$ nstitute for Behavioral Medicine Research, \\ The Ohio State University, Columbus, OH, USA; ${ }^{3}$ Division of Biosciences, The Ohio State University, College of Dentistry, \\ Columbus, OH, USA; ${ }^{4}$ Center for Brain and Spinal Cord Repair, The Ohio State University, Columbus, OH, USA
}

The population of aged individuals is increasing worldwide and this has significant health and socio-economic implications. Clinical and experimental studies on aging have discovered myriad changes in the brain, including reduced neurogenesis, increased synaptic aberrations, higher metabolic stress, and augmented inflammation. In rodent models of aging, these alterations are associated with cognitive decline, neurobehavioral deficits, and increased reactivity to immune challenges. In rodents, caloric restriction and young blood-induced revitalization reverses the behavioral effects of aging. The increased inflammation in the aged brain is attributed, in part, to the resident population of microglia. For example, microglia of the aged brain are marked by dystrophic morphology, elevated expression of inflammatory markers, and diminished expression of neuroprotective factors. Importantly, the heightened inflammatory profile of microglia in aging is associated with a 'sensitized' or 'primed' phenotype. Mounting evidence points to a causal link between the primed profile of the aged brain and vulnerability to secondary insults, including infections and psychological stress. Conversely, psychological stress may also induce aging-like sensitization of microglia and increase reactivity to secondary challenges. This review delves into the characteristics of neuroinflammatory signaling and microglial sensitization in aging, its implications in psychological stress, and interventions that reverse aging-associated deficits.

Neuropsychopharmacology Reviews (2017) 42, 318-333; doi:I0.1038/npp.2016.185; published online 12 October 2016

\section{INTRODUCTION}

Advances in the biomedical sciences have led to a significant increase in the elderly population. For instance, $13 \%$ of the population in the United States was estimated to be 65 years old or older in 2010. Moreover, the population 85 years and over is projected to rise from 5.5 million in 2010 to 19 million by 2050 (Federal Interagency Forum on AgingRelated Statistics, 2012). This increasing trend in the older population is palpable on a global scale and can be attributed to overall reduction in mortality and a longer life span (Federal Interagency Forum on Aging-Related Statistics, 2012). Increase in life span, however, is met with a newer challenge to extend health span of the aging individuals. In other words, slowing aging in itself is not sufficient unless paralleled with healthy aging. Although aging is not a disease, it is a significant risk factor for functional decline, affective impairments, exaggerated response to illnesses, dementia, and overall vulnerability for diseases (Hayflick, 2007; Seals and Melov, 2014). Conversely, life events

*Correspondence: Dr JP Godbout, Department of Neuroscience, The Ohio State University, 231 IBMR Bld, 460 Medical Center Drive Columbus, OH 43210, USA, Tel: +614 293 3456, Fax: +614 366 2097, E-mail: jonathan.godbout@osumc.edu

Received 17 May 2016; revised 22 August 2016; accepted 25 August 2016; accepted article preview 8 September 2016 associated with psychological stress and injury can also lead to accelerated aging-associated impairments and dementia (Epel et al, 2004; Smith et al, 2013). This review presents (1) findings from clinical and animal studies that have helped elucidate the dynamics and mechanisms underlying aging, (2) the role of microglia in enhanced inflammatory signaling in the aged brain, (3) the role of caloric restriction and blood-borne factors on delaying aging, and (4) the effects of psychological stress on premature aging and aging-associated impairments.

\section{CLINICAL FEATURES OF NORMAL AGING}

Aging is a progressive natural phenomenon characterized by anatomical and functional decline paralleled with cognitive impairments. Despite identification of a constellation of changes associated with aging, a standard definition of normal aging has yet to reach consensus (Fjell et al, 2014). In humans, the distinguishing criteria for normal vs pathological aging are: central nervous system (CNS) injury, amyloid plaques (based on positron emission tomography (PET)), neurodegeneration, neuropsychiatric conditions, dementia, and impaired performance on cognitive tests (Arani et al, 2015; Fabbri et al, 2016; Tegeler et al, 2016). Thus, the applied definition of normal aging may include an absence of 
frank pathology and dementia, and presence of cognitive decline (eg, executive function) that is common to the aging population. An accurate understanding of normal aging may be hindered by cross-sectional studies, which fail to consider individual differences, such as, genetics, socioeconomic status, environment, and lifestyle. For instance, in comparison with longitudinal design, cross-sectional analysis was found to overestimate age-associated cognitive decline (Singh-Manoux et al, 2012). There is also a lack of consensus on the age of onset of cognitive decline. For example, a crosssectional analysis showed that episodic memory decline begins as early as 20 s, whereas longitudinal analysis of the same project estimated cognitive decline to occur around the age of 60 (Ronnlund et al, 2005). Aging-associated neuroanatomical changes also revealed sexual dimorphism in that males were likely to undergo greater reduction in brain elasticity and stiffness than their female counterparts (Arani et al, 2015; Sack et al, 2009). Thus, the confounding variability presented by age, sex, individual differences, and methods of analysis highlights that although aging is a natural phenomenon, it is not a uniform phenomenon. Nevertheless, there is mounting evidence revealing the overall anatomical and behavioral changes associated with aging.

\section{Neuroanatomical and Behavioral Changes in Aging: Evidence from Clinical Studies}

Neuroimaging studies have confirmed volumetric changes in brain regions of the elderly (Storsve et al, 2014; Zhang et al, 2016). Overcoming the drawbacks of cross-sectional studies that have largely dominated clinical studies on aging, newer research based on the longitudinal studies has reported significant tissue atrophy in the temporal and occipital regions in non-pathological aging (Pfefferbaum et al, 2013; Storsve et al, 2014). In an elegant study based on the idea that replicating DNA in human neurons incorporate atmospheric ${ }^{14} \mathrm{C}$ radioactive carbon, Spalding et al (2013) showed increased ${ }^{14} \mathrm{C}$ levels in human hippocampal genomic DNA, indicative of postnatal neurogenesis, into at least the fifth decade of life (Spalding et al, 2013). New neurons were generated at a rate of $1.75 \%$ during adulthood with a modest but significant decline with old age. These results support previous findings of postnatal neurogenesis in humans, and underscore its quantitative and qualitative changes in aging (Knoth et al, 2010). Decelerated neurogenesis and hippocampal atrophy are associated with memory deficits in humans (Cameron and McKay, 1999).

Corresponding with the volumetric changes and deficits associated with neurogenesis, elderly individuals show rapid impairments in cognitive and affective functioning. Cognitive decline, primarily in executive functioning and memory formation, is one of the most pronounced consequences of aging (Daselaar et al, 2006; Hedden and Gabrieli, 2004; Townsend et al, 2006). Although aging itself is not associated with decline in affective functioning, aged individuals, compared with the young, are more vulnerable to depressive symptoms associated with physical illnesses, and life events (English and Carstensen, 2015; Fiske et al, 2009, 2013). Furthermore, elderly individuals with depression also have accelerated cognitive decline. Overall, these findings indicate an age-dependent association between anatomical changes, and cognitive and affective functioning in aging (Gualtieri and Johnson, 2008).

\section{Immune Dysregulation in Aging: Evidence from Clinical Studies}

Peripheral immune system. One of the hallmarks of aging is elevated oxidative stress and inflammation (Finkel and Holbrook, 2000). Indeed, the term 'inflamm-aging' has been coined to describe the heightened inflammatory status that is characteristic of the aging process and is attributed to cumulative exposure to antigens and stress (Franceschi et al, 2000). On one hand, there is evidence of aging-associated deterioration of the adaptive immune system that affects T-cell and B-cell functions (Gibson et al, 2009; GrubeckLoebenstein et al, 2009). These changes are attributed to aging-associated immune senescence that impairs the ability to fight infections and produce antibodies critical for the efficacy of vaccines (Grubeck-Loebenstein et al, 2009). On the other hand, there is evidence indicating enhanced presence of innate immune cells and circulating cytokines in the elderly. This change may indicate a shift away from antigen-specific adaptive immune response in the aged individuals to a more innate immunity-driven response that is associated with heightened inflammation. For example, increased number of monocytes, neutrophils, and elevated levels of circulating cytokines have been consistently reported in elderly individuals (Leng et al, 2005; Roubenoff et al, 1998; Tan et al, 2007). Notably, higher levels of inflammation in the elderly are associated with neurobehavioral complications. For instance, a recent cross-sectional study investigating the association between inflammatory markers and executive functioning in an elderly population indicated an age-associated increase in the serum expression of C-reactive protein (CRP), IL-6 and IL-10. Elevated levels of these cytokines were inversely associated with executive performance on neuropsychological tests (Tegeler et al, 2016). In addition, a separate multistage population-based study reported that serum levels of IL- 6 and soluble TNF $\alpha$ could be used as an inflammatory index to predict mortality in the elderly (Varadhan et al, 2014). Taken together, these findings reveal an increase in systemic levels of inflammatory signaling molecules in elderly humans.

Central immune system. Heightened inflammatory signaling in aging is evident in the peripheral system and the CNS alike. For instance, microarray studies of the adult and aged human prefrontal cortex reported age-dependent increased expression of inflammation-associated genes, such as, NFKB, Toll-like-receptor (TLR)-4, IL-1R, and GFAP (Primiani et al, 2014). Similarly, age-related increase in IL-6, oxidative damage, and concurrent reduction in total antioxidant 
capacity levels was reported in the cerebrospinal fluid of healthy adults (Guest et al, 2014). These findings collectively indicate an age-associated increase in inflammatory signaling and oxidative stress in the aging brain and in the CNS as a whole.

The increased neuroinflammatory profile has primarily been attributed to aging-associated changes in microglia, the innate immune cells of the CNS. During embryogenesis, microglia originate from yolk sac-derived myeloid progenitors and take up residence in the brain (Kierdorf et al, 2012). Although initially considered 'quiescent' cells primarily responsible for clearing cellular debris in the brain, microglia are now known as dynamic players in synaptic pruning, maintaining homeostasis and are primary responders to insult and injury in the CNS (Lou et al, 2016; Nimmerjahn et al, 2005; Paolicelli et al, 2011). Under homeostatic conditions, microglia display a ramified phenotype, marked by numerous processes. In response to inflammatory insult, these cells undergo morphological alterations, marked by shorter, thicker processes and enhanced expression of inflammatory markers (Streit et al, 1999). Histological examination of the human postmortem brain samples have revealed pronounced morphological changes in microglia of the aged brain. These changes are marked by deramification, cytoplasmic fragmentation, and shortening of cellular processes even in absence of frank pathology (Streit et al, 2004). Taken together, molecular analysis of the brain and cerebrospinal fluid, paralleled by imaging and histological studies, reveal an augmented inflammatory profile of the aged human brain.

Current clinical evaluations of microglia activation have relied largely on TSPO (Translocator Protein $(18 \mathrm{kDa})$ ) binding activity detected via PET. TSPO is a peripheral benzodiazepine receptor expressed on the outer mitochondrial layer of microglia, and is believed to be upregulated during microglial activation (Rupprecht et al, 2010). Several PET scan studies have revealed increased receptor binding of the TSPO ligands, R- $\left[{ }^{11} \mathrm{C}\right] \mathrm{PK} 11195$ and $\left[{ }^{11} \mathrm{C}\right]$ vinpocetine, in the cortical and subcortical brain regions of healthy elderly participants (Gulyas et al, 2011; Schuitemaker et al, 2012). Increased TSPO binding has been interpreted as enhanced microglia activation. Although some PET studies have shown increased TSPO ligand-binding activity in the brains of older adults, other studies did not (Suridjan et al, 2014). These discrepancies have been attributed to the difference in ligand types, off-target binding (such as the vascular endothelial cells), uneven distribution of the radioactive ligand in the brain parenchyma, and tissue-dependent differences in ligand affinity (Suridjan et al, 2014; Turkheimer et al, 2015). For example, use of higher-affinity TSPO ligands increased vascular binding, in turn masking ligand binding in the microglia (Rizzo et al, 2014). Overall, PET studies have indicated that increased TSPO binding may not necessarily reflect increased TSPO expression in vivo. Furthermore, increased TSPO expression may not be indicative of the inflammatory phenotype of microglia (Scholz et al, 2015). Taken together, although TSPO binding may be optimized as a method to examine microglia, the aforementioned methodological variabilities and interpretations demand a thorough and critical evaluation of the findings.

\section{NEUROIMMUNE DYSREGULATION IN AGING: EXPERIMENTAL EVIDENCE}

Animal models have played a significant role in recapitulating the neurological, inflammatory and behavioral correlates of human aging. In particular, rodents serve as the most popular animal models owing to their shorter life span, manipulability, convenience, and relative similarities to aging in humans. For instance, the average lifespan curve for mice (Mus musculus) is consistent with that of humans, indicating similar patterns of decline in health span between the two species (Mitchell et al, 2015). Despite these similarities, there also exist inherent differences in patterns of aging among species and strains. Indeed, the use of different strains of rodents has generated significant variability in research, hindering interpretation of the findings. For example, a longevity study performed on 19 strains of specificpathogen-free mice and rats showed marked differences in lifespan ranging from 312 to 782 days within the mouse strains (Festing and Blackmore, 1971). Moreover, sex was a strong determinant of lifespan, as females outlived the males in 14 out of the 19 strains, although no significant difference was detected in the remaining 5 strains (Festing and Blackmore, 1971). In an extensive longitudinal and crosssectional study conducted on 30 most commonly used strains of inbred mice, the authors showed strain and sex differences in lifespan, physiological, and histopathological changes (Sundberg et al, 2011). Additional determinants of aging and longevity include, microbiome, housing environment etc. As most animals used in aging studies are 'aged' in animal facilities, female mice are fairly popular due to their lower propensity to engage in aggressive behavior or fighting. However, given the sexual dimorphism, aging in one sex may not be representative of aging in the strain as a whole. An extensive resource on aging in various mouse strains is available in the Mouse Phenome Database provided by the Jackson Laboratory, Maine. Taken together, these studies elucidate numerous ways in which aging may manifest in different species and sexes. Therefore, it is important to note that although rodents serve as an important model for studying aging, the variability in the models demands critical consideration.

Nonetheless, decades of research has made enormous strides in advancing the scientific understanding of aging in humans and rodents. Corresponding with clinical findings in the human elderly, aged mice showed deficits in neurogenesis and memory (van Praag et al, 2005). Animal studies have implicated microglial dysregulation in aging-associated neurogenic and behavioral deficits (Streit et al, 2008). For instance, microglia depletion in hippocampal culture from aged mice, but not from young mice, promoted formation of neurospheres (indicative of neural progenitor cell 
proliferation), suggesting an anti-neurogenic role of microglia in the aged brain (Vukovic et al, 2012). Although the precise role of microglia in neurogenesis remains unclear, microglia are known to undergo several transcriptional and morphological changes that contribute to aberrant immunological and neuronal responses in aging. These changes, collectively referred to as 'priming', are discussed below.

\section{The Primed Microglia}

Microglia are strictly regulated by factors within the CNS microenvironment during homeostasis (Biber et al, 2007). With aging, microglia take on a 'primed' phenotype, which is characterized by an exaggerated and uncontrolled inflammatory response to an immune stimulus (Perry and Holmes, 2014). Early reports on aging showed increased IL-1 $\beta$, reactive oxygen species, and lipid peroxidation levels that corresponded with impaired long-term potentiation (LTP) in the dentate gyrus of aged rats (Murray and Lynch, 1998). Furthermore, intraventricular administration of IL- $1 \beta$ was sufficient to induce lipid peroxidation in adult rats, highlighting the causal relationship between inflammatory signaling and metabolic stress, the two major characteristics of aging (Giulian et al, 1986). Notably, elevated IL-1 $\beta$ was reported in some studies and not others. For instance, aged ( 22 month old) Wistar and Fisher 344 rats (Gemma et al, 2005; Lynch, 1999) were reported to show elevated brain IL-1 $\beta$, whereas (23-26 month old) Fisher $344 \times$ BN F1 and Fisher 344 rats (Barrientos et al, 2009; Gee, Ding, and Keller, 2006) and (18-22 month old) BALB/c and C57BL/6 mice did not exhibit increased baseline levels of brain IL-1 $\beta$ (Hascup et al, 2016; Huang et al, 2008; Wynne et al, 2010). Whether baseline IL- $1 \beta$ is elevated in the aged brain may depend on the strain and age of animals used in the study. Nevertheless, it is important to note that the primed profile associated with microglia in aging does not refer to an enhanced immune response at baseline, rather it refers to an exaggerated inflammatory response to an immune challenge/stimulus (Cunningham et al, 2005).

Microglia priming has been most widely characterized in the context of systemic inflammation and neurodegenerative conditions. Repeated exposure to systemic immune challenge induces microglia priming. For example, a single LPS injection increased serum levels of IL-1 $\beta$ with no concurrent changes in brain IL-1 $\beta$ levels. However, a second injection (24 h later) significantly increased brain IL- $1 \beta$ levels with a much smaller increase in serum IL-1 $\beta$ (Puntener et al, 2012). Similarly, in a neurodegenerative model of ME7 prion disease mice, microglia displayed an ameboid, deramified morphology, distinct from the ramified microglia in the control mice. This morphological alteration was associated with a greater increase in brain IL- $\beta$ following LPS injections in the ME7 mice, compared with the saline control (Cunningham et al, 2005). LPS-induced increase in brain IL-1 $\beta$ was also associated with reduced locomotor activity in the ME7 mice, indicating that microglial priming in the prion disease model induces exaggerated immune response as well as sickness behavior (Combrinck et al, 2002). These findings show that central and peripheral immune changes can trigger priming in microglia that display an exaggerated inflammatory response in response to an otherwise mild immune challenge.

\section{Exaggerated Inflammatory Response to Immune Challenge in Aging}

A consequence of microglia priming in aging is an increased reactivity to peripheral immune challenge (Barrientos et al, 2011; Frank et al, 2010; Sierra et al, 2007). For instance, systemic injection of LPS caused an exaggerated and sustained neuroinflammatory response in the aged mice (Godbout et al, 2005). This exaggerated expression of cytokines in the aged mice was associated with the prolonged sickness (Godbout et al, 2005) and depressive-like behavior (Godbout et al, 2008). In addition, minocycline, a tetracycline antibiotic with anti-inflammatory actions on microglia, reduced LPS-induced augmentation of inflammatory mediators, such as IL- $1 \beta$, indoleamine 2,3 dioxygenase and TLR2, indicating that the neuroinflammatory response and sickness behavior following LPS is mediated by microglial activation (Henry et al, 2008). Subsequent studies showed that the excessive IL-1 $\beta$ protein produced in the aged brain after LPS challenge was derived from the primed (MHCII positive) microglia (Henry et al, 2009). It is important to note that LPS enhances expression of pro-inflammatory (eg, IL-1 $\beta$ ) and anti-inflammatory (eg, IL-10) mediators in aged mice compared with the adult (Henry et al, 2009). Although IL-10 expression may indicate a compensatory step against the pro-inflammatory response, IL-1 $\beta$ production in aged mice was not attenuated despite presence of IL-10 (Henry et al, 2009). A recent study showed that microglial IL-10 binds to astrocytes that modulate microglial inflammatory signaling in a transforming growth factor (TGF)- $\beta$-dependent manner (Norden et al, 2014). Aging was associated with reduced IL-10 receptor on aged astrocytes that resulted in a failure to resolve microglia activation in the aged brain (Norden et al, 2016). Overall, these findings indicate that increased immune reactivity to systemic immune challenge in the aged brain is attributed to primed microglia. Several reports have elucidated (and have postulated) the mechanisms of peripheral-to-central immune signaling in the context of sickness behavior and cognitive impairments. Peripheral inflammatory mediators, such as cytokines, engage in communication with the CNS via (i) vagal afferents containing cytokine receptors that serve as direct transmitters of peripheral immune signals to the brain, (ii) direct diffusion into the brain via leaky blood-brain-barrier in the circumventricular organs, such as, paraventricular nucleus of the hypothalamus and area postrema (iii) active energy-dependent transport of cytokines by brain endothelial cells, and (iv) propagation of peripheral cytokine signals via brain endothelial cell receptors (Dilger and Johnson, 2008; Maier, 2003; Miller et al, 2009). 


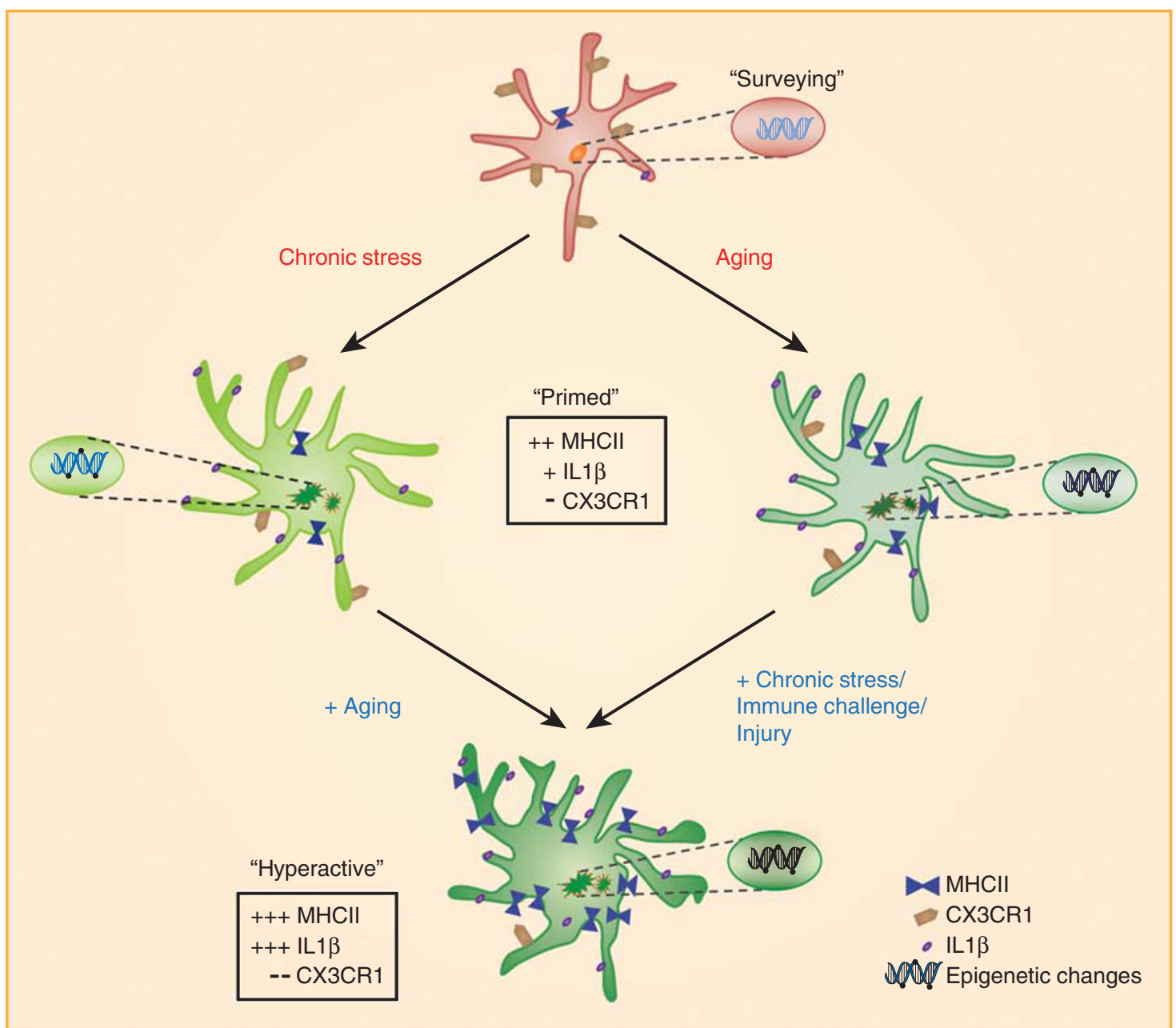

Figure 1. Aging and environmental factors are intertwined in a dynamic, bidirectional relationship. Under homeostatic conditions, microglia are highly dynamic cells, constantly 'surveying' the brain microenvironment. Clinical and animal studies support findings of microglial priming (or 'sensitization') with aging. The 'primed' microglia are characterized by a dystrophic morphology including, de-ramified processes, spherical cell body, and fragmented cytoplasm (Streit et al, 2004). Associated with these morphological alterations are biochemical changes, such as elevated expression of antigen presentation molecules (MHCII), Toll-like receptors, pro-inflammatory cytokines (IL-1 $\beta)$, reduced expression of regulatory molecules (CX3CR1 and CD200R) (Frank et al, 2006; Maher et al, 2004), DNA methylation changes and telomere shortening (Flanary and Streit, 2003; Zannas et al, 2015). Microglia of the aged brain also show deficient phagocytic activity and impaired mobility under baseline (Damani et al, 2011). This primed profile of microglia has been documented in aging and chronic psychological stress. Primed microglia are vulnerable to subsequent immune stimuli, such as immune challenge, stress, and aging. As such, upon exposure to these stimuli, the primed microglia take on a 'hyperactive' state marked by exaggerated pro-inflammatory response and resistance to regulation (Barrientos et al, 2009; Frank, Barrientos, et al, 2010; Godbout et al, 2005; Kinsey et al, 2008; Willette et al, 2012; Wynne et al, 2010).

Further evidence implicating peripheral immune stimulation and microglia priming comes from surgical stress and cognitive decline, both of which are common among older adults (Moller et al, 1998). In rodent models, aged but not young adult rats displayed memory impairments and elevated hippocampal IL-1 $\beta$ levels 4 days after laparotomy (Barrientos et al, 2012). Moreover, intracisternal IL-1 receptor antagonist attenuated the laparotomy-induced hippocampal IL- $1 \beta$ and reversed memory deficits, further highlighting the exaggerated neuroinflammatory response to a peripheral challenge (Barrientos et al, 2012). Taken together, central inflammatory signaling in the aged brain can be comprehended in twofolds: (i) microglia take on a primed phenotype as a function of aging, (ii) and exhibit an exaggerated inflammatory response when triggered by an immune challenge (Figure 1).

The primed profile of microglia associated with aging is also evident in CNS pathologies. For example, microglia from healthy aged mice exhibited a gene expression profile similar to that of microglia from the APP-PS1 mice, a model of Alzheimer's disease. Namely, both conditions showed enriched expression of genes associated with lysosomal function, oxidative phosphorylation, integrins, and signaling molecules implicated in Alzheimer's Disease (Holtman et al, 2015). Furthermore, compared with the young brain, microglia from the aged brain were found to internalize $53 \%$ fewer amyloid beta plaques, suggesting inefficient phagocytosis in aged microglia (Njie et al, 2012). These 
aged microglia also expressed significantly higher levels of TNF $\alpha$ and IL6 in response to ex vivo LPS (Njie et al, 2012). A series of studies using a ME7 prion disease model showed dystrophic morphology of microglia and enhanced expression of inflammatory mediators such as IL- $1 \beta$ and COX-2 following in vivo LPS challenge. The exaggerated inflammatory changes in ME7 mice were also associated with impairments in spatial learning (Cunningham et al, 2009). These characteristics, representative of microglial priming and subsequent hyperactivation, are similar to those in the aged brain (Cunningham et al, 2005).

Despite some morphological and transcriptional overlapping between microglia in normal aging and pathological aging (eg, neurodegenerative conditions), there exist significant differences in the progression of aging. As such, although microglia in animal models of neurodegenerative conditions serve as examples of the primed phenotype, these microglia represent priming under more chronic conditions, compared with priming as a result of normal aging. It is also important to consider that the primed microglia associated with normal aging may respond differently based on the immune challenge. Acute challenge, such as Escherichia coli in aged rats (discussed above) induced exaggerated neuroinflammatory response and memory impairments that were completely resolved by 14 days (Barrientos et al, 2009). However, chronic immune challenge, such as, Bacillus Calmette-Guerin triggered prolonged depressive-like behavior that persisted beyond 21 days (Kelley et al, 2013). Thus, the inflammatory response of the primed microglia in aging is dependent on the duration and intensity of immune stimulation.

\section{Markers of Microglia Priming}

The primed profile of microglia has primarily been characterized based on gene expression, morphology, and mobility. Microglia under normal aging (ie, aging in absence of neurodegeneration) showed upregulation of genes associated with antigen presentation, such as MHCII, CD86, and CIITA (Frank et al, 2006; Godbout et al, 2005; VanGuilder et al, 2011), and suppression of anti-inflammatory genes, such as IL-10 and CD200 (Frank et al, 2006). Similarly, TLR 1, 2, 4, 7 and co-receptor CD14, which together comprise antigen receptors of the innate immunity, were also upregulated in the aged mice (Letiembre et al, 2007). The microglial morphology in the aged rodent brain was first characterized via electron microscopy, revealing their spherical morphology that was distinct from microglia of the young adult brain (Vaughan and Peters, 1974). Furthermore, the number of microglia was found to increase by $65 \%$ between the ages of 3 and 27 months (Vaughan and Peters, 1974). This morphological profile of the aged microglia first reported in rats has also been confirmed in mice, gerbils, and dogs (Hwang et al, 2008; Korhonen et al, 1997; Norden and Godbout, 2013; Streit and Xue, 2010). Taken together, microglia undergo aging-associated morphological changes that are concurrent with increased expression of inflammatory markers.

In addition to the augmented inflammatory profile, the dynamic behavior of microglia is also altered in aging. In the healthy adult brain, microglia are found in a highly dynamic state, constantly surveying the CNS microenvironment (Nimmerjahn et al, 2005). In the aged mice, however, microglia show significantly diminished mobility under baseline conditions. For example, although microglia from young mice responded to extracellular ATP by extension of old processes and formation of new, aged microglia were found to withdraw and even eliminate their existing processes (Damani et al, 2011). In response to in vivo focal laser injury, microglia from both young and aged mice accumulated around the injury site 4 days post injury. However, microglia in the young mice, but not in the aged showed disaggregation at 16 days post injury, suggesting prolonged accumulation of the aged microglia and impaired ability for disaggregation (Damani et al, 2011). Together, these findings indicate that microglia of the aged brain show an abnormally sustained response to non-homeostatic conditions, such as injury.

\section{Transcriptional Profile of the Aged Brain: Close Ties with an Inflammatory Profile}

Concurrent with changes in microglial antigen presentation markers and morphology, transcriptional alterations have also been reported via microarray studies in aged humans and animals. In healthy humans between the ages 26 and 106 years, genes associated with inflammatory response and metabolism were significantly upregulated in the prefrontal cortex as a function of age (Lu et al, 2004). Most notable increases occurred in cytokines, complement components and cell adhesion-related genes, although remarkable decreases were observed in genes involved in synaptic transmission, vesicular transport, and protein signaling ( $\mathrm{Lu}$ et al, 2004). Interestingly, gene expression profile changes in aging occurred in a region-dependent and sexually dimorphic manner. For example, in the human brain, 5029 genes in the superior frontal gyrus, compared with 1110 in the entorhinal cortex, were altered with age. Moreover, the male brains showed greater alterations in overall gene expression, altough increased immune activation was characteristic of both sexes (Berchtold et al, 2008). Together, these findings indicate aging-associated changes that vary across brain regions and sexes. Furthermore, these changes are associated with an overall increase in neuroinflammatory signaling that can be attributed to the primed profile of microglia.

Corresponding with these data, microarray results from the mice brain also showed an age-associated upregulation of genes that code for lysozyme, complement, MHC proteins, and others implicated in immune function (Godbout et al, 2005). The only report examining the brain-region-specific transcriptional profile of microglia demonstrated a heightened baseline expression of genes associated with 
metabolism and immune response in the cerebellum and hippocampus (Grabert and Michoel, 2016). Notably, aging induced an overall increase in the expression of immunoreceptor tyrosine-based activation motif (ITAM) with no change in immunoreceptor tyrosine-based inhibitory motif. For example, there was an age-dependent increase in the expression of amplifying receptors (such as, TREM1, SIRPB1a, etc), and a corresponding reduction (eg, CD200 receptor) or stable expression (eg, CD300a) of inhibitory receptors in microglia. This selective increase in the ITAM genes is suggestive of an immune-vigilant phenotype of the aged microglia. In the same study, the hippocampal microglia showed a $30 \%$ decline in overall gene expression between the ages 4 and 22 months, a finding the authors referred to as 'potential disengagement of aged hippocampal microglia with their environment compared to their young adult counterparts' (Grabert and Michoel, 2016). These aging-induced region-dependent changes hold significant implications in the health of the elderly. For example, the hippocampus is particularly susceptible to age-associated functional impairments and overt pathology such as neuronal degeneration (Mosher and Wyss-Coray, 2014; Vukovic et al, 2012; West et al, 1994). Taken together, aging induces region-dependent changes in the expression of inflammatory markers that are responsible for the hypervigilant immune status of the aged brain.

\section{Microenvironmental Regulation of Microglia in the Aging Brain}

Although the precise mechanisms underlying heightened neuroinflammation in aging remain elusive, one of the potential contributors is the impaired regulatory signaling between microglia and other cell types in the brain. For example, neurons and microglia are engaged in constant interaction via secreted and membrane-bound ligands and receptors. Neuronal signals regulating microglial activation have been categorized as Off signals and On signals. The former refer to constitutively expressed signals (such as, CX3CL1 and CD200) that maintain the homeostatic functions of microglia, whereas the latter refer to inducible signals (such as, ATP and TREM2 ligand) that trigger pro- and anti-inflammatory activation in microglia (Biber et al, 2007).

Microglia are the only CNS cells to express the fractalkine receptor $\mathrm{CX}_{3} \mathrm{CR}_{1}$, a constitutively expressed marker that serves a critical role in postnatal synaptic development and behavioral outcomes. Indeed, mice lacking $\mathrm{CX}_{3} \mathrm{CR}_{1}$ undergo deficient synaptic pruning and brain development, subsequently resulting in abnormal social behavior (Paolicelli et al, 2011; Zhan et al, 2014). Microglial $\mathrm{CX}_{3} \mathrm{CR}_{1}$ interaction is mediated via its ligand $\mathrm{CX}_{3} \mathrm{CL}_{1}$, which is constitutively expressed by neurons as a membrane-bound and a secreted protein (Hughes et al, 2002). Aged mice, but not adults, showed reduced baseline levels of $\mathrm{CX}_{3} \mathrm{CL}_{1}$ that remained unaltered after a systemic LPS challenge (Wynne et al, 2010). LPS-injected aged mice, however, showed protracted downregulation of $\mathrm{CX}_{3} \mathrm{CR}_{1}$ and reduced social behavior, which was accompanied by elevated IL- $1 \beta$ and reduced TGF $\beta$ (Wynne et al, 2010). Furthermore, in vitro treatment of microglial cells with LPS followed by TGF $\beta$ significantly attenuated LPS-induced IL-1 $\beta$ expression (Wynne et al, 2010). Indeed, the critical role of $\mathrm{CX}_{3} \mathrm{CR}_{1}$ in microglial regulation and prevention of neurotoxicity has been repeatedly demonstrated in various in vivo models of neuroinflammation (Cardona et al, 2006). Taken together, these findings provide evidence for a key immunomodulatory role of $\mathrm{CX}_{3} \mathrm{CR}_{1}$ in absence of which microglia of the aged brain take on a dysregulated, pro-inflammatory phenotype.

In addition to fractalkine proteins, CD200, one of the best-studied members of the immunoglobulin superfamily, is another critical component of microglial regulation. In the CNS, CD200 and its receptor CD200r are expressed by neurons and microglia, respectively, and this interaction is crucial to the maintenance of microglial quiescence (Biber et al, 2007). Indeed, despite normal lifespan and no obvious behavioral abnormalities, CD200-knockout mice have deramified microglia with upregulated levels of CD11b and CD45 at baseline, overall indicative of an activated phenotype (Hoek et al, 2000). Compared with young adults, aged rats showed reduced neuronal CD200 that was associated with the increased microglial MHCII expression (Lyons et al, 2007). IL-4 treatment of cultured neurons and intracerebroventricular administration of IL-4 markedly increased CD200 expression in hippocampal neurons (Lyons et al, 2007). IL-4 is a cytokine associated with microglia regulation. Aged mice failed to upregulate IL-4R $\alpha$ in response to LPS, and did not elicit an alternative (regulatory) immune response to ex vivo IL-4 (Fenn et al, 2012). Moreover, IL-4 knockout mice had reduced baseline expression of CD200 at mRNA and protein levels, which was associated with enhanced glial production of IL- $1 \beta$, TNF $\alpha$, and IL- 6 following LPS treatment (Lyons et al, 2009). Furthermore, this heightened inflammatory profile was associated with exacerbated sickness behavior, lack of social exploration, and enhanced anxiety-like behavior (Lyons et al, 2009). Aging-induced impairment in IL-4 signaling that occurs following LPS treatment is also evident in traumatic spinal cord injury in aged mice. For example, compared with adult mice, the aged mice showed deficient IL-4R $\alpha$ expression, that corresponded with reduced arginase production and impaired functional recovery following spinal cord injury (Fenn et al, 2014). These findings suggest an aginginduced impairment of microglial regulation, primarily marked by failure to revert to the homeostatic state after the resolution of inflammation. Taken together, these findings indicate that a deficient CD200-CD200r signaling in the brain may contribute to the elevated inflammatory phenotype associated with aging. Indeed, microglial priming in aging could be attributed to impairments in $\mathrm{CX}_{3} \mathrm{CL}_{1}$ $\mathrm{CX}_{3} \mathrm{CR}_{1}$ and CD200-CD200r signaling between neurons and microglia. 


\section{Microglial Senescence and Hypoactivation: Implications for Aging}

Although the immunological profile of the aged brain is generally discussed in the context of microglial priming and enhanced pro-inflammatory signaling, some findings indicate that microglia undergo senescence as a function of aging. Some reports have implicated the deramified morphology and cytoplasmic fragmentation of the aged microglia in microglial senescence (Streit et al, 2004). Microglial senescence is also associated with reduced proliferation. For example, repeated nerve crush injury resulted in the increased microglial proliferation in young rats, but not in the aged (Miller and Streit, 2007). A primary feature of cellular senescence is reduced potential for cell replication due to telomere shortening. Indeed, ageassociated increase in telomerase activity and reduction in telomere length has been reported in the rat brain (Flanary and Streit, 2003), indicating that microglia of the aged brain have a reduced potential for proliferation. In addition, microglial senescence has also been associated with increased oxidative stress accumulating over cellular lifespan (Streit et al, 2008). Overall, these reports of senescence are suggestive of functional deficiency and reduced proliferation of microglia with age. On the contrary, aging has also been associated with an increase, rather than a decrease, in microglial population (Gebara et al, 2013; Mouton et al, 2002; Tremblay et al, 2012). This paradox of microglial priming and proliferation concurrent with senescence in the aging brain remains unclear (Streit and Xue, 2010).

Although microglia hyperactivation is detrimental to normal brain function, microglia hypoactivation, as described above, may also be associated with undesirable health outcomes. Some clinical reports have implicated depression with lower levels of inflammatory markers such as, CRP and IL-6 (Almeida et al, 2009; Whooley et al, 2007). In addition, a randomized trial using TNF $\alpha$ antagonist as a treatment for depression failed to alleviate disease symptoms (Raison $e t$ al, 2013). These findings suggest that the lowering inflammatory response may not necessarily be the global solution to mental health impairments. Interestingly, therapeutic treatments such as, electroconvulsive therapy and transcranial current stimulation, in rats were associated with a pro-inflammatory phenotype of microglia, marked by morphological alterations, and increased MHCII expression and proliferation (Jansson et al, 2009; Rueger et al, 2012). On the basis of these findings, microglia activation at optimal levels may serve to alleviate depression. However, it is important to note that these therapeutic interventions were tested on naive animals, and therefore, may not reflect the effects that may occur in animals with depressive-like behavior. Nevertheless, it is important to note that microglial activation is associated with production of trophic factors, such as brain-derived neurotrophic factor (BDNF), which is crucial to the development of neurons and synaptic plasticity (Parkhurst et al, 2013; Trang et al, 2009). Overall, these reports indicate that microglial activation may present as a problem or as a resolution to a problem. For example, some individuals diagnosed with major depression may show reduced levels of inflammatory markers, whereas others may show elevated levels. In light of these findings, the idea of a personalized treatment approach has also been proposed to address the discrepancies in disorders such as, major depression (Yirmiya et al, 2015).

As in the context of psychological disorders, microglia hypoactivation has also been reported in aging and aging-associated pathologies. For example, PS1-APP mice (a model of Alzheimer's Disease) showed an age-dependent reduction in receptors and enzymes involved in beta amyloid degradation, although still maintaining elevated levels of cytokine (Hickman et al, 2008). Although this disease model is not representative of normal aging, these findings overall revealed the heterogeneous nature of microglia activation, in which the microglia may be functionally hyperactive for cytokine production, whereas hypoactive for clearance of plaques and debris. Overall, these findings indicate that microglial activation cannot be simply categorized as harmful or beneficial. Instead microglial activation at optimal levels is necessary for the maintenance of homeostatic functions and overall health.

\section{REVERSAL OF AGING-ASSOCIATED DEFICITS VIA IMMUNE ALTERATIONS}

\section{Rejuvenation of the Aged Brain via Blood-Borne Factors}

Aging-associated decline in physiology and function also occurs beyond the brain in peripheral organs such as muscles, heart, and bone. Replenishing the circulatory system with young blood has been shown to rejuvenate peripheral organs and reverse functional deficits in animals (Sinha et al, 2014). Recent studies from parabiosis models of heterochronically paired animals (aged and young animals that share the circulatory system via vascular anastomosis) showed increased neurogenesis and improved cognitive functions in the aged mice following exposure to young blood (Villeda et al, 2014). These findings were the first to implicate blood-borne factors in reversing the effects of aging in brain regions, such as the hippocampus, that are located in close proximity to vascular supply. Further studies identified the role of peripheral blood cells, as well as secreted blood factors in aging-induced changes in the brain. Indeed, gene expression analysis of the choroid plexus, a brain region marked by epithelial lining that serves as a neurovascular interface, revealed an aging-induced upregulation of interferon-I (IFN-I) and downregulation of interferon-II response genes (Baruch et al, 2014). Moreover, neutralizing antibodies against IFN-I restored growth factor levels and cognitive functioning in aged mice, thus demonstrating the role of blood-derived factors in aging-induced neurological deficits (Baruch et al, 2014). Additional evidence for the role of blood-borne systemic factors in aging-induced 


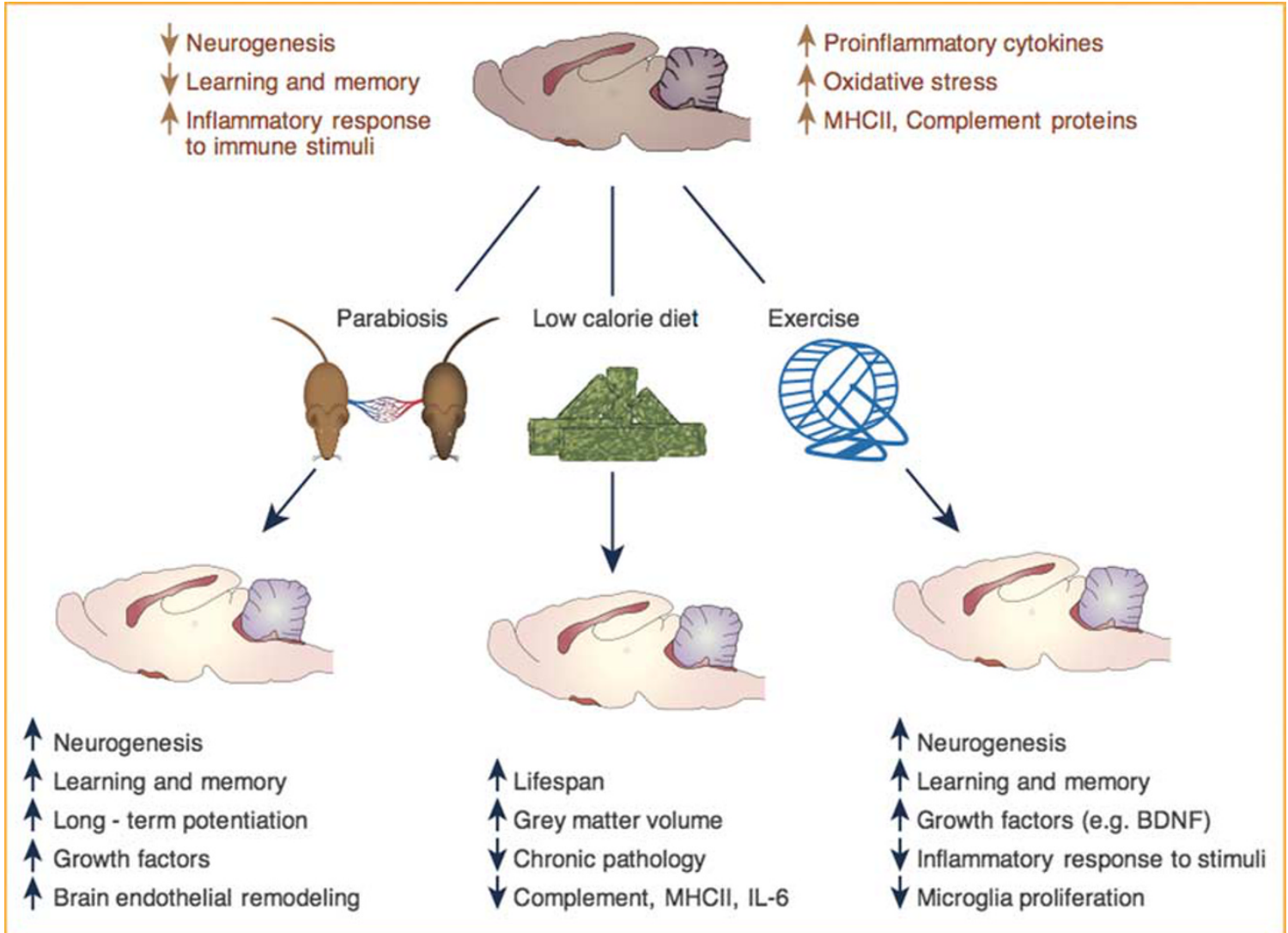

Figure 2. Reversal of aging-associated deficits via immune alterations. Aging is associated with reduced neurogenesis, impaired learning and memory, as well as increased pro-inflammatory markers, antigen presentation molecules and oxidative stress. Recent findings from parabiosis models (left) have shown that exposure to young blood restores neurogenesis, learning and memory and neuronal functions in older mice via increase in growth factors and endothelial remodeling in older mice (Baruch et al, 2014; Katsimpardi et al, 2014; Villeda et al, 2011). Caloric restriction (middle) is associated with prolonged life, increased gray matter volume, improved motor function, and reduced chronic pathology (eg, neoplasia) and inflammatory markers (complement proteins, antigen presentation markers, and pro-inflammatory cytokines) in rodents, non-human primates, and humans (Colman et al, 2009; Willette et al, 2012; Witte et al, 2009). Clinical and animal reports show that aerobic exercise (right) in humans and voluntary running in rodents is associated with enhanced neurogenesis, improved learning and memory, increased hippocampal BDNF, and dampened inflammatory response to immune challenge and microglia proliferation (Barrientos et al, 2011; Colcombe et al, 2003; Gebara et al, 2013).

impairments was provided by Villeda et al (2011) who showed that older mice that share a blood supply with younger mice show increased neurogenesis, enhanced LTP and improved cognitive functioning. Conversely, younger mice heterochronically paired with older mice showed reduced cell proliferation in the dentate gyrus and impaired neurogenesis. Furthermore, plasma transfer from younger mice into the aged was sufficient to replicate the findings from the parabiosis experiments, elucidating the role of blood-borne soluble factors, and not blood cells, in reversing aging-associated impairments in the brain (Villeda et al, 2011). In particular, aging-associated increase in systemic levels of CCL11 was associated with impaired neurogenesis and learning deficits, which were reversed by systemic and intrahippocampal administration of neutralizing anti-CCL11 antibody in the aged mice (Villeda et al, 2011). Corresponding with these findings, another study using parabiosis showed brain endothelium remodeling and restoration of cerebral blood flow in aged mice exposed to young blood (Katsimpardi et al, 2014). The study attributed the aging-associated vascular and blood flow impairments specifically to reduced circulating levels of GDF11, a secreted protein of the TGF family (Katsimpardi et al, 2014). Although the definitive role of GDF11 in aging-induced vascular deficits was challenged by subsequent studies, the role of blood-borne factors in aging-associated physiological and behavioral alterations in the brain has garnered further credence and offers therapeutic promise (Castellano et al, 2015; Egerman et al, 2015). Indeed, clinical trials involving plasma and plasma protein transfer from younger individuals are already underway for the treatment of aging-associated diseases such as, Alzheimer's disease. Examples of the projects include: The Plasma for Alzheimer SymptoM Amelioration (PLASMA) Study (clinicaltrials.gov; NCT02256306) and A Study to Evaluate Albumin and Immunoglobulin in Alzheimer's Disease (AMBAR; clinicaltrials.gov; NCT01561053). Taken together, emerging evidence supports that alterations in systemic factors in aging drive neurogenic and functional impairments, and that manipulation of these factors may allow for reversal of aging-induced dysregulation (Figure 2). 


\section{Reversal of Aging-Associated Deficits via Caloric Restriction}

In addition to exposure to young blood, caloric restriction has also been known to enhance longevity and improve cognitive functioning via immunological alterations. Caloric restriction involves reduction of consumed calories without inducing malnutrition (Trepanowski et al, 2011). According to a recent study on post-menopausal obese females, a lowcalorie diet for 12 weeks led to a significant weight reduction that corresponded with improved memory, enhanced gray matter volume and functional connectivity in the hippocampus and inferior frontal gyrus (Prehn et al, 2016). Interestingly, these cognitive changes were no longer present over a prolonged period of time, despite the maintenance of reduced weight (Prehn et al, 2016). These findings demonstrated, for the first time, that caloric restriction-induced enhanced cognitive functioning in humans is a result of weight reduction rather than sustained reduced weight. Similarly, another study also reported a memory improvement of $20 \%$ in normal and overweight elderly females, following $30 \%$ caloric restriction for a period of 3 months (Witte et al, 2009). These changes were associated with reduced plasma levels of insulin and inflammatory markers such as CRP (Witte et al, 2009). These caloric restrictionassociated changes were not reported in subjects treated with unsaturated fatty acid diet (diet composition: 20\% increase in unsaturated fatty acid, no change in total fat), indicating that reduced consumption of overall calories, and not just reduced saturated fatty acids, improves memory performance in humans.

The benefits of caloric restriction observed in humans have also been reported in other species, such as rats, mice, and monkeys (Colman et al, 2009; Richardson et al, 2015; Youm et al, 2016). In a 20-year-long longitudinal study on Rhesus monkeys, the survival rates of monkeys under calorierestriction diet (30\% of normal diet) and those under normal diet were reported to be $80 \%$ and $50 \%$, respectively (Colman et al, 2009). Furthermore, monkeys under the caloric restriction condition had delayed onset of aging-associated pathology, such as, neoplasia, cardiovascular diseases, and glucose-associated impairments, and showed higher gray matter volume in subcortical regions (Colman et al, 2009). In a separate study, functional neuroimaging results showed that caloric restriction in older monkeys reduced iron deposition in the brain and improved motor performance on multiple measures (Kastman et al, 2012). Similarly, caloric restriction in mice was associated with life span extension by 20\% (Patel et al, 2015). In a separate study on rats, a $10 \%$ caloric restriction prolonged lifespan at the same level as $40 \%$ caloric restriction (Richardson et al, 2015). Interestingly however, prolonged life in the $40 \%$ caloric restriction rats, but not in 10\%, was accompanied by significant reduction in aging-associated pathology, such as neoplasia, indicating that higher caloric restriction induces longevity while delaying chronic pathology (Richardson et al, 2015). Taken together, findings of increased longevity have been reported in several species and have been corroborated by multiple studies.

Transcriptomic and immunohistochemical evaluations of aged mice and rats indicate that the benefits of caloric restriction are mediated via immune and metabolic pathways (Martin et al, 2016). Indeed, the first study examining the effects of caloric restriction on the transcriptome profile of aged mice revealed key reversal of aging-associated markers, such as complement subunits, lysozyme, antigen presentation proteins, heat shock proteins, and other inflammation and stress-related genes (Lee et al, 2000). These findings were further confirmed via subsequent microarray studies, as well as network-based investigations (Swindell, 2009). Furthermore, caloric restriction-associated reversal of aging-induced brain atrophy was also associated with reduced IL-6 levels, thus highlighting the role of immune mediators (Willette et al, 2010). Taken together, clinical findings supporting the benefits of caloric restriction are in line with animal studies, which revealed that the resulting delay in mortality and neuroprotective effects are mediated by reversal of inflammatory and metabolic changes associated with aging. Overall, studies reveal that rejuvenation of the aged brain by caloric restriction and by exposure to young blood are both mediated by overall attenuation of inflammatory signaling in the aged brain.

\section{The Benefits of Exercise in Delaying Aging}

The clinical benefits of aerobic exercise on preventing brain tissue loss have been reported in older adults via crosssectional and longitudinal studies (Colcombe et al, 2003; Colcombe et al, 2006). For example, 6 months of aerobic exercise was associated with significant increases in brain oxygen uptake, and cortical gray and white matter volume in older adults (Colcombe et al, 2006). Although exercise has long been known to improve immunity, cognitive functioning and overall health, the exact mechanisms underlying these benefits remain elusive. In this context, exercise paradigms using aged animals have identified potential factors and mechanisms that may elucidate the relationship between exercise and aging. Older mice that engaged in voluntary running showed significant improvement in spatial memory and increased neurogenesis compared to non-runners (van Praag et al, 2005). Exercise was also shown to prevent age-associated increase in microglia proliferation (Gebara et al, 2013). In aged rats, exercise prevented learning impairments following peripheral immune challenge, and this effect was associated with increased expression of hippocampal BDNF (Barrientos et al, 2011). The same study also demonstrated that exercise prevents microglia priming in aged rats. For example, hippocampal IL- $1 \beta$ levels were reduced in old runners, but not in old sedentary rats. Microglia from runner rats also had lower IL- $1 \beta, \mathrm{TNF} \alpha$, and IL-6 mRNA following ex vivo LPS challenge (Barrientos et al, 2011). Overall, these findings indicate that exercise increases neurogenesis and improves cognitive functioning in aged animals, while reducing microglia priming associated with 
aging. Importantly, these benefits of exercise indicate that the overall aging-associated deficits may be a cumulative consequence of aging and sedentary lifestyle. Indeed, findings from caloric restriction experiments have shown that reduction in caloric intake can significantly prolong lifespan and prevent microglia priming associated with age. Overall, (i) higher caloric expenditure via exercise and (ii) reduced caloric intake via caloric restriction both confer their benefits by attenuating the enhanced inflammatory profile of the aged brain (Figure 2).

\section{AGING IN THE CONTEXT OF PSYCHOLOGICAL STRESS}

The rejuvenating effects of caloric restriction and exercise indicate that aging, a natural and progressive phenomenon, is yet susceptible to environmental factors and lifestyle, of which stress is an example. Indeed, mounting evidence from clinical and animal studies has begun to shine a light on the intertwined relationship between aging and psychological stress.

\section{Overlapping Characteristics of Chronic Stress and Aging: Clinical Evidence}

Recent clinical findings showed that the epigenetic profile (such as, DNA methylation in glucocorticoid (GC) responsive regions) of subjects exposed to lifetime stress resembled the epigenetic changes in aging-associated diseases (Zannas et al, 2015). In addition, the methylation profile of individuals exposed to lifetime stress displayed an accelerated epigenetic aging profile, which was not present in individuals exposed to acute stress (Zannas et al, 2015). These findings indicate that prolonged exposure to stress may pose a significant risk for premature aging in adults. The potential link with chronic stress and premature aging is also reported in the context of telomere shortening in humans. A recent study showed that chronic stress associated with long-term caregiving for demented spouse was associated with shortened telomere length, lower levels of telomerase activity, and increased oxidative stress (Epel et al, 2004). Psychological stress is known to trigger inflammatory response and premature shortening of telomere length, leading to cellular senescence, which is characteristic of aging (Lindqvist et al, 2015). Moreover, the inflammatory profiles altered during stress and during aging revealed striking similarities (Jurgens and Johnson, 2012). For example, postmortem brain analysis of depressed suicide victims showed an activated morphological profile of microglia similar to that in the aged brain (Streit et al, 2004; Torres-Platas et al, 2014). Taken together, the inflammatory and metabolic correlates of chronic stress in adults are similar to those in older individuals, indicating that adults exposed to chronic stress are vulnerable to premature aging.

\section{Pro-inflammatory Effects of Psychological Stress: Experimental Evidence}

Animal studies have played an instrumental role in highlighting the aberrant effects of psychological stress on the immune system. Rodents exposed to repeated social defeat stress and inescapable foot-shock exhibit heightened neuroinflammatory responses that underlie prolonged behavioral deficits. For example, microglia in the stressed brain undergo profound morphological changes, marked by large amoeboid cell bodies and thicker processes (Frank et al, 2007; Wohleb et al, 2011). These morphological alterations were associated with the classical activation profile, characterized by the increased expression of antigen presentation molecule (MHCII), cell surface markers (TLR4 and CD14), and pro-inflammatory cytokines and chemokines (IL-1 $\beta$, TNF $\alpha$, IL-6, and CCL2) (Frank et al, 2007; Ramirez et al, 2016; Wohleb et al, 2011). Moreover, the elevated expression of pro-inflammatory cytokines in microglia was found to be maintained for at least 24 days after the cessation of stress (Ramirez et al, 2015). This primed or 'sensitized' profile of microglia in psychological stress was responsible for the long-term re-establishment of anxiety in mice initially exposed to repeated social defeat stress (Wohleb et al, 2014). For example, primed microglia from the stressexposed mice, but not naive mice, elicited an exaggerated inflammatory response to acute social defeat stress, and this response was sufficient for the recurrence of anxiety-like behavior (Wohleb et al, 2014). Stress-induced microglia priming also increased vulnerability to subsequent peripheral immune challenge. For example, intraperitoneal LPS induced a markedly higher production of microglial IL- $1 \beta, \mathrm{TNF} \alpha$, iNOS, and CD14 in stress-exposed mice compared with naive mice (Wohleb et al, 2012). Microglial activation and inflammatory signaling following psychological stress has been reported in mice and rats alike, and has also been recapitulated in other models, such as restraint stress and foot-shock stress (Frank et al, 2007; Hinwood et al, 2012; Kreisel et al, 2014; Tynan et al, 2010; Voorhees et al, 2013). Taken together, psychological stress leads to activation of the microglia, which then take on a primed profile, and elicit an exaggerated inflammatory response when exposed to subsequent immune challenge. This evidence of microglia priming is a key characteristic in both, stress and aging (Figure 2).

\section{The Overlap between Psychological Stress and Aging: Experimental Evidence}

The heightened inflammatory signaling observed in humans under stress and aging has been well recapitulated in animal models. Compared with the younger mice, aged mice showed increased anxiety-like behavior following repeated social defeat stress (Kinsey et al, 2008). Furthermore, the peripheral myeloid cells from the aged mice exposed to repeated social defeat were more resistant to the apoptotic effects of GCs (further discussion on the immune effects of GCs is provided later in this review). The effects of aging 
have been also documented in other cell types. For example, natural killer cell and lymphocyte activity, which are reported to diminish with age in monkeys and mice, were further attenuated following restraint stress in aged mice (Coe, 2004; Padgett, 1998). A longitudinal study on aging in Rhesus monkeys showed exacerbated brain volume loss and stress reactivity (as indicated by increased hostility, resistance, and fear response) in response to social stress (Kastman et al, 2012). These effects were not observed in monkeys placed on $30 \%$ caloric restriction, suggesting that caloric restriction may attenuate the stress-induced behavioral and anatomical impairments associated with aging (Willette et al, 2012). Overall, culminating evidence points to an interaction between stress and aging such that the elevated immune profile of the aged brain is further augmented in animals exposed to psychological stressors (Figure 2).

Although stress can accelerate and mimic aspects of aging, the converse also holds true. In other words, the effects of stress in older adults are more pronounced than in younger adults. Indeed, older adults were found to display higher levels of circulating corticosterone at baseline that was associated with hippocampal atrophy and memory deficits (Lupien et al, 1998). This age-associated increase in corticosterone was also reported in rats, and was associated with a decline in hippocampal neurogenesis (Cameron and McKay, 1999; Sapolsky, 1992). Moreover, corticosterone depletion via adrenalectomy rescued these neurogenesis deficits in aged rats to a level comparable to the young adults (Cameron and McKay, 1999). Increased corticosterone has also been associated with the impaired hippocampal neurogenesis and neuronal development in the context of psychological stress (Lehmann et al, 2013; McKim et al, 2016). Together, these findings provide the evidence of increased corticosterone in psychological stress, as well as in aging. Although historically characterized as anti-inflammatory, GCs exert dynamic actions on the immune system. Indeed, it is important to note the seemingly paradoxical and context-dependent effects of GCs. For example, one of the mechanisms underlying the anti-inflammatory effects of GCs is the inhibition of nuclear factor- $\mathrm{\kappa B}(\mathrm{NF}-\mathrm{\kappa B})$, a major transcription factor for the inflammatory-response genes (De Bosscher et al, 2000). However, accumulating evidence indicates that prior exposure to GCs can instead promote $\mathrm{NF}-\mathrm{\kappa B}$ activity and increase the pro-inflammatory response to subsequent LPS, indicating that GCs can exert a priming effect to subsequent immune challenge (Frank et al, 2010; Munhoz et al, 2006). Moreover, pharmacological or surgical depletion of GC signaling before stress prevented the microglial expression of pro-inflammatory cytokines in response to LPS (Frank et al, 2012).

These reports of elevated GCs in the aging brain provide significant insight into the role of GCs in age-associated priming. Relevant to this, hippocampal expression of nuclear GC receptors has been reported to increase with age in rats (Barrientos et al, 2015). As GC receptors reside in the cytoplasm in their inactive form and in the nucleus in their active form, the increased presence of nuclear GC receptors is indicative of increased GC receptor signaling. Indeed, the enzyme, 11 $\beta$-hydroxysteroid dehydrogenase (11 $\beta$-HSD1), involved in the conversion of the inactive corticosterone into its active form, was increased with aging (Barrientos et al, 2015), and aging-associated memory impairments were prevented in 11 $\beta$-HSD1-knockout animals (Yau et al, 2015). Furthermore, enhanced GC receptor activity in aging was associated with increased microglial expression of MHCII, which was reversed by GC receptor antagonist (Barrientos et al, 2015). Taken together, these findings highlight the role of increased GC signaling in aging-associated microglia priming. More importantly, as GCs are the primary responders in stress regulation, these reports reveal a dynamic and bidirectional relationship between psychological stress and aging, in which one may exacerbate the effects of the other (Lupien et al, 2009).

\section{CONCLUSION}

Aging is a progressive phenomenon and not a disease by itself. However, an aged brain is significantly vulnerable to immune stimuli in comparison to a younger brain. For example, stimuli otherwise considered mild for an adult brain can elicit deleterious consequences in the aging brain. Given the unprecedented increase in lifespan, the health effects of aging are more significant than ever, to global health and economy. Furthermore, increased lifespan is accompanied by increased exposure to lifetime stress, which in turn leads to the accelerated aging, primarily marked by premature senescence, diseases, and poor quality of life. Dysregulation of microglia, the innate immune cells of the brain, is a key factor underlying the deleterious consequences of aging and stress. Microglia of the aged brain take on a 'primed' or 'sensitized' phenotype, characterized by dystrophic morphology, progressive accumulation of metabolic stress, increased cell-surface expression of antigen recognition molecules, and an exaggerated inflammatory response to immune challenge. This augmented inflammatory profile of microglia in the aged brain is associated with impairments in synaptic plasticity, neurogenesis, and emotional and cognitive deficits. Recent studies have provided significant insight into these physiological and biochemical alterations that occur with age.

Indeed, advancements in aging research have shown significant therapeutic promise. Recent findings in animals indicating that manipulation of the peripheral immune system may restore cognitive functioning and cellular activity in the brain have generated the idea of blood-induced rejuvenation of the aged brain. As such, clinical trials using blood-borne components have been launched as potential therapies against Alzheimer's Disease and age-related macular degeneration (clinicaltrials.gov; NCT02256306, NCT01561053, NCT 00766649). Furthermore, exercise, physical activity, and caloric restriction in humans and animals have also been shown to promote healthy aging. A clearer understanding of the mechanisms underlying aging 
is imperative to tackling aging-associated disorders and functional impairments, and thus promoting the development of a healthy society.

\section{FUNDING AND DISCLOSURE}

Dr Jonathan Godbout's work was supported by NIA grant (R0-1AG033028). Dr John Sheridan's work was supported by NIMH grant (R01-MH093473 and R01-MH097243). The authors declare no conflict of interest.

\section{REFERENCES}

Almeida OP, Norman PE, Allcock R, van Bockxmeer F, Hankey GJ, Jamrozik K et al (2009). Polymorphisms of the CRP gene inhibit inflammatory response and increase susceptibility to depression: the Health in Men Study. Int J Epidemio/ 38: 1049-1059.

Arani A, Murphy MC, Glaser KJ, Manduca A, Lake DS, Kruse SA et al (2015). Measuring the effects of aging and sex on regional brain stiffness with MR elastography in healthy older adults. Neuroimage 111: 59-64.

Barrientos RM, Frank MG, Crysdale NY, Chapman TR, Ahrendsen JT, Day HE et al (2011). Little exercise, big effects: reversing aging and infection-induced memory deficits, and underlying processes. J Neurosci 31: 11578-11586.

Barrientos RM, Frank MG, Hein AM, Higgins EA, Watkins LR, Rudy JW et al (2009). Time course of hippocampal IL-1 beta and memory consolidation impairments in aging rats following peripheral infection. Brain Behav Immun 23: 46-54.

Barrientos RM, Hein AM, Frank MG, Watkins LR, Maier SF (2012). Intracisternal interleukin-1 receptor antagonist prevents postoperative cognitive decline and neuroinflammatory response in aged rats. J Neurosci 32: 14641-14648.

Barrientos RM, Thompson VM, Kitt MM, Amat J, Hale MW, Frank MG et al (2015). Greater glucocorticoid receptor activation in hippocampus of aged rats sensitizes microglia. Neurobiol Aging 36: 1483-1495.

Baruch K, Deczkowska A, David E, Castellano JM, Miller O, Kertser A et al (2014). Aging. Aging-induced type I interferon response at the choroid plexus negatively affects brain function. Science 346: 89-93.

Berchtold NC, Cribbs DH, Coleman PD, Rogers J, Head E, Kim R et al (2008). Gene expression changes in the course of normal brain aging are sexually dimorphic. Proc Natl Acad Sci USA 105: 15605-15610.

Biber K, Neumann H, Inoue K, Boddeke HW (2007). Neuronal 'On' and 'Off' signals control microglia. Trends Neurosci 30: 596-602.

Cameron HA, McKay RD (1999). Restoring production of hippocampal neurons in old age. Nat Neurosci 2: 894-897.

Cardona AE, Pioro EP, Sasse ME, Kostenko V, Cardona SM, Dijkstra IM et al (2006). Control of microglial neurotoxicity by the fractalkine receptor. Nat Neurosci 9: 917-924.

Castellano JM, Kirby ED, Wyss-Coray T (2015). Blood-Borne Revitalization of the Aged Brain. JAMA Neurol 72: 1191-1194.

Coe $C L$ (2004). Biological and social predictors of immune senescence in the aged primate. Mech Ageing Dev 125: 95-98.

Colcombe SJ, Erickson KI, Raz N, Webb AG, Cohen NJ, McAuley E et al (2003). Aerobic fitness reduces brain tissue loss in aging humans. J Gerontol A Biol Sci Med Sci 58: 176-180.

Colcombe SJ, Erickson KI, Scalf PE, Kim JS, Prakash R, McAuley E et al (2006). Aerobic exercise training increases brain volume in aging humans. J Gerontol $A$ Biol Sci Med Sci 61: 1166-1170.

Colman RJ, Anderson RM, Johnson SC, Kastman EK, Kosmatka KJ, Beasley TM et al (2009). Caloric restriction delays disease onset and mortality in rhesus monkeys. Science 325: 201-204.

Combrinck Ml, Perry VH, Cunningham C (2002). Peripheral infection evokes exaggerated sickness behaviour in pre-clinical murine prion disease. Neuroscience 112: 7-11.

Cunningham C, Campion S, Lunnon K, Murray CL, Woods JF, Deacon RM et al (2009). Systemic inflammation induces acute behavioral and cognitive changes and accelerates neurodegenerative disease. Biol Psychiatry 65: 304-312.

Cunningham C, Wilcockson DC, Campion S, Lunnon K, Perry VH (2005). Central and systemic endotoxin challenges exacerbate the local inflammatory response and increase neuronal death during chronic neurodegeneration. J Neurosci 25: 9275-9284.

Damani MR, Zhao L, Fontainhas AM, Amaral J, Fariss RN, Wong WT (2011). Age-related alterations in the dynamic behavior of microglia. Aging Cell 10: 263-276.
Daselaar SM, Fleck MS, Dobbins IG, Madden DJ, Cabeza R (2006). Effects of healthy aging on hippocampal and rhinal memory functions: an event-related fMRI study. Cereb Cortex 16: 1771-1782.

De Bosscher K, Vanden Berghe W, Haegeman G (2000). Mechanisms of anti-inflammatory action and of immunosuppression by glucocorticoids: negative interference of activated glucocorticoid receptor with transcription factors. J Neuroimmunol 109: 16-22.

Dilger RN, Johnson RW (2008). Aging, microglial cell priming, and the discordant central inflammatory response to signals from the peripheral immune system. J Leukoc Biol 84: 932-939.

Egerman MA, Cadena SM, Gilbert JA, Meyer A, Nelson HN, Swalley SE et al (2015). GDF11 Increases with Age and Inhibits Skeletal Muscle Regeneration. Cell Metab 22: $164-174$

English T, Carstensen LL (2015). Does positivity operate when the stakes are high? Health status and decision making among older adults. Psychol Aging 30: 348-355.

Epel ES, Blackburn EH, Lin J, Dhabhar FS, Adler NE, Morrow JD et al (2004). Accelerated telomere shortening in response to life stress. Proc Natl Acad Sci USA 101: 17312-17315.

Fabbri E, An Y, Zoli M, Tanaka T, Simonsick EM, Kitner-Triolo MH et al (2016). Association between accelerated multimorbidity and age-related cognitive decline in older baltimore longitudinal study of aging participants without dementia. I Am Geriatr Soc 64: 965-972.

Federal Interagency Forum on Aging-Related Statistics. Older Americans, (2012) Key Indicators of Well-Being: Washington, D.C.

Fenn AM, Hall JC, Gensel JC, Popovich PG, Godbout JP (2014). IL-4 signaling drives a unique arginase+/IL-1beta+ microglia phenotype and recruits macrophages to the inflammatory CNS: consequences of age-related deficits in IL-4Ralpha after traumatic spinal cord injury. J Neurosci 34: 8904-8917.

Fenn AM, Henry CJ, Huang Y, Dugan A, Godbout JP (2012). Lipopolysaccharideinduced interleukin (IL)-4 receptor-alpha expression and corresponding sensitivity to the M2 promoting effects of IL-4 are impaired in microglia of aged mice. Brain Behav Immun 26: 766-777.

Festing MF, Blackmore DK (1971). Life span of specified-pathogen-free (MRC category 4) mice and rats. Lab Anim 5: 179-192.

Finkel T, Holbrook NJ (2000). Oxidants, oxidative stress and the biology of ageing. Nature 408: 239-247.

Fiske A, Gatz M, Pedersen NL (2003). Depressive symptoms and aging: the effects of illness and non-health-related events. J Gerontol B Psychol Sci Soc Sci 58: P320-P328.

Fiske A, Wetherell JL, Gatz M (2009). Depression in older adults. Annu Rev Clin Psychol 5: 363-389.

Fjell AM, McEvoy L, Holland D, Dale AM, Walhovd KB (2014). What is normal in normal aging? Effects of aging, amyloid and Alzheimer's disease on the cerebral cortex and the hippocampus. Prog Neurobiol 117: 20-40.

Flanary BE, Streit WJ (2003). Telomeres shorten with age in rat cerebellum and cortex in vivo. J Anti Aging Med 6: 299-308.

Franceschi C, Bonafe M, Valensin S, Olivieri F, De Luca M, Ottaviani E et al (2000). Inflamm-aging. An evolutionary perspective on immunosenescence. Ann NY Acad Sci 908: 244-254.

Frank MG, Baratta MV, Sprunger DB, Watkins LR, Maier SF (2007). Microglia serve as a neuroimmune substrate for stress-induced potentiation of CNS pro-inflammatory cytokine responses. Brain Behav Immun 21: 47-59.

Frank MG, Barrientos RM, Biedenkapp JC, Rudy JW, Watkins LR, Maier SF (2006). mRNA up-regulation of MHC II and pivotal pro-inflammatory genes in normal brain aging. Neurobiol Aging 27: 717-722.

Frank MG, Barrientos RM, Watkins LR, Maier SF (2010). Aging sensitizes rapidly isolated hippocampal microglia to LPS ex vivo. J Neuroimmunol 226: 181-184.

Frank MG, Miguel ZD, Watkins LR, Maier SF (2010). Prior exposure to glucocorticoids sensitizes the neuroinflammatory and peripheral inflammatory responses to E. coli lipopolysaccharide. Brain Behav Immun 24: 19-30.

Frank MG, Thompson BM, Watkins LR, Maier SF (2012). Glucocorticoids mediate stress-induced priming of microglial pro-inflammatory responses. Brain Behav Immun 26: 337-345.

Gebara E, Sultan S, Kocher-Braissant J, Toni N (2013). Adult hippocampal neurogenesis inversely correlates with microglia in conditions of voluntary running and aging. Front Neurosci 7: 145.

Gee JR, Ding Q, Keller JN (2006). Age-related alterations of Apolipoprotein E and interleukin-1beta in the aging brain. Biogerontology 7: 69-79.

Gemma C, Fister M, Hudson C, Bickford PC (2005). Improvement of memory for context by inhibition of caspase-1 in aged rats. Eur J Neurosci 22: 1751-1756.

Gibson KL, Wu YC, Barnett Y, Duggan O, Vaughan R, Kondeatis E et al (2009). B-cell diversity decreases in old age and is correlated with poor health status. Aging Cell 8: 18-25. 
Giulian D, Baker TJ, Shih LC, Lachman LB (1986). Interleukin 1 of the central nervous system is produced by ameboid microglia. J Exp Med 164: 594-604.

Godbout JP, Chen J, Abraham J, Richwine AF, Berg BM, Kelley KW et al (2005). Exaggerated neuroinflammation and sickness behavior in aged mice following activation of the peripheral innate immune system. Faseb j 19: 1329-1331.

Godbout JP, Moreau M, Lestage J, Chen J, Sparkman NL, O'Connor J et al (2008). Aging exacerbates depressive-like behavior in mice in response to activation of the peripheral innate immune system. Neuropsychopharmacology 33: 2341-2351.

Grabert K, Michoel T (2016). Microglial brain region-dependent diversity and selective regional sensitivities to aging. Nat Neurosci 19: 504-516.

Grubeck-Loebenstein B, Della Bella S, Iorio AM, Michel JP, Pawelec G, Solana R (2009). Immunosenescence and vaccine failure in the elderly. Aging Clin Exp Res 21: 201-209.

Gualtieri CT, Johnson LG (2008). Age-related cognitive decline in patients with mood disorders. Prog Neuropsychopharmacol Biol Psychiatry 32: 962-967.

Guest J, Grant R, Mori TA, Croft KD (2014). Changes in oxidative damage, inflammation and $[N A D(H)]$ with age in cerebrospinal fluid. PLoS One 9: e85335.

Gulyas B, Vas A, Toth M, Takano A, Varrone A, Cselenyi Z et al (2011). Age and disease related changes in the translocator protein (TSPO) system in the human brain: positron emission tomography measurements with [11C]vinpocetine. Neuroimage 56: 1111-1121.

Hascup ER, Wang F, Kopchick JJ, Bartke A (2016). Inflammatory and Glutamatergic Homeostasis Are Involved in Successful Aging. J Gerontol A Biol Sci Med Sci 71: 281-289.

Hayflick L (2007). Biological aging is no longer an unsolved problem. Ann NY Acad Sci 1100: 1-13.

Hedden T, Gabrieli JD (2004). Insights into the ageing mind: a view from cognitive neuroscience. Nat Rev Neurosci 5: 87-96.

Henry CJ, Huang Y, Wynne A, Hanke M, Himler J, Bailey MT et al (2008). Minocycline attenuates lipopolysaccharide (LPS)-induced neuroinflammation, sickness behavior, and anhedonia. J Neuroinflammation 5: 15.

Henry CJ, Huang Y, Wynne AM, Godbout JP (2009). Peripheral lipopolysaccharide (LPS) challenge promotes microglial hyperactivity in aged mice that is associated with exaggerated induction of both pro-inflammatory $\mathrm{IL}-1$ beta and antiinflammatory IL-10 cytokines. Brain Behav Immun 23: 309-317.

Hickman SE, Allison EK, El Khoury J (2008). Microglial dysfunction and defective beta-amyloid clearance pathways in aging Alzheimer's disease mice. J Neurosci 28: 8354-8360.

Hinwood M, Morandini J, Day TA, Walker FR (2012). Evidence that microglia mediate the neurobiological effects of chronic psychological stress on the medial prefrontal cortex. Cereb Cortex 22: 1442-1454.

Hoek RM, Ruuls SR, Murphy CA, Wright GJ, Goddard R, Zurawski SM et al (2000). Down-regulation of the macrophage lineage through interaction with OX2 (CD200). Science 290: 1768-1771.

Holtman IR, Raj DD, Miller JA, Schaafsma W, Yin Z, Brouwer N et al (2015). Induction of a common microglia gene expression signature by aging and neurodegenerative conditions: a co-expression meta-analysis. Acta Neuropathol Commun 3: 31.

Huang Y, Henry CJ, Dantzer R, Johnson RW, Godbout JP (2008). Exaggerated sickness behavior and brain proinflammatory cytokine expression in aged mice in response to intracerebroventricular lipopolysaccharide. Neurobiol Aging 29: 1744-1753.

Hughes PM, Botham MS, Frentzel S, Mir A, Perry VH (2002). Expression of fractalkine (CX3CL1) and its receptor, CX3CR1, during acute and chronic inflammation in the rodent CNS. Glia 37: 314-327.

Hwang IK, Lee CH, Li H, Yoo KY, Choi JH, Kim DW et al (2008). Comparison of ionized calcium-binding adapter molecule 1 immunoreactivity of the hippocampal dentate gyrus and CA1 region in adult and aged dogs. Neurochem Res 33: 1309-1315.

Jansson L, Wennstrom M, Johanson A, Tingstrom A (2009). Glial cell activation in response to electroconvulsive seizures. Prog Neuropsychopharmacol Biol Psychiatry 33: 1119-1128.

Jurgens HA, Johnson RW (2012). Dysregulated neuronal-microglial cross-talk during aging, stress and inflammation. Exp Neurol 233: 40-48.

Kastman EK, Willette AA, Coe CL, Bendlin BB, Kosmatka KJ, McLaren DG et al (2012). A calorie-restricted diet decreases brain iron accumulation and preserves motor performance in old rhesus monkeys. J Neurosci 32: 11897-11904.

Katsimpardi L, Litterman NK, Schein PA, Miller CM, Loffredo FS, Wojtkiewicz GR et al (2014). Vascular and neurogenic rejuvenation of the aging mouse brain by young systemic factors. Science 344: 630-634.

Kelley KW, O'Connor JC, Lawson MA, Dantzer R, Rodriguez-Zas SL, McCusker RH (2013). Aging leads to prolonged duration of inflammation-induced depressionlike behavior caused by Bacillus Calmette-Guerin. Brain Behav Immun 32: 63-69.
Kierdorf K, Erny D, Goldmann T, Sander V, Schulz C, Perdiguero EG et al (2012). Microglia emerge from erythromyeloid precursors via Pu.1- and Irf8-dependent pathways. Nat Neurosci 16: 273-280.

Kinsey SG, Bailey MT, Sheridan JF, Padgett DA (2008). The inflammatory response to social defeat is increased in older mice. Physiol Behav 93: 628-636.

Knoth R, Singec I, Ditter M, Pantazis G, Capetian P, Meyer RP et al (2010). Murine features of neurogenesis in the human hippocampus across the lifespan from 0 to 100 years. PLoS One 5: e8809.

Korhonen P, Helenius M, Salminen A (1997). Age-related changes in the regulation of transcription factor NF-kappa B in rat brain. Neurosci Lett 225: 61-64.

Kreisel T, Frank MG, Licht T, Reshef R, Ben-Menachem-Zidon O, Baratta MV et al (2014). Dynamic microglial alterations underlie stress-induced depressive-like behavior and suppressed neurogenesis. Mol Psychiatry.

Lee CK, Weindruch R, Prolla TA (2000). Gene-expression profile of the ageing brain in mice. Nat Genet 25: 294-297.

Lehmann ML, Brachman RA, Martinowich K, Schloesser RJ, Herkenham M (2013). Glucocorticoids orchestrate divergent effects on mood through adult neurogenesis. J Neurosci 33: 2961-2972.

Leng S, Xue QL, Huang Y, Semba R, Chaves P, Bandeen-Roche K et al (2005). Total and differential white blood cell counts and their associations with circulating interleukin-6 levels in community-dwelling older women. J Gerontol A Biol Sci Med Sci 60: 195-199.

Letiembre M, Hao W, Liu Y, Walter S, Mihaljevic I, Rivest S et al (2007). Innate immune receptor expression in normal brain aging. Neuroscience 146: 248-254.

Lindqvist D, Epel ES, Mellon SH, Penninx BW, Revesz D, Verhoeven JE et al (2015). Psychiatric disorders and leukocyte telomere length: Underlying mechanisms linking mental illness with cellular aging. Neurosci Biobehav Rev 55: 333-364.

Lou N, Takano T, Pei Y, Xavier AL, Goldman SA, Nedergaard M (2016). Purinergic receptor P2RY12-dependent microglial closure of the injured blood-brain barrier. Proc Natl Acad Sci USA 113: 1074-1079.

Lu T, Pan Y, Kao SY, Li C, Kohane I, Chan J et al (2004). Gene regulation and DNA damage in the ageing human brain. Nature 429: 883-891.

Lupien SJ, de Leon M, de Santi S, Convit A, Tarshish C, Nair NP et al (1998). Cortisol levels during human aging predict hippocampal atrophy and memory deficits. Nat Neurosci 1: 69-73.

Lupien SJ, McEwen BS, Gunnar MR, Heim C (2009). Effects of stress throughout the lifespan on the brain, behaviour and cognition. Nat Rev Neurosci 10: 434-445.

Lynch MA (1999). What is the biological significance of an age-related increase in IL-1beta in hippocampus? Mol Psychiatry 4: 15-18.

Lyons A, Downer EJ, Crotty S, Nolan YM, Mills KH, Lynch MA (2007). CD200 ligand receptor interaction modulates microglial activation in vivo and in vitro: a role for IL-4. J Neurosci 27: 8309-8313.

Lyons A, McQuillan K, Deighan BF, O'Reilly JA, Downer EJ, Murphy AC et al (2009). Decreased neuronal CD200 expression in IL-4-deficient mice results in increased neuroinflammation in response to lipopolysaccharide. Brain Behav Immun 23: 1020-1027.

Maher FO, Martin DS, Lynch MA (2004). Increased IL-1beta in cortex of aged rats is accompanied by downregulation of ERK and PI-3 kinase. Neurobiol Aging 25: 795-806.

Maier SF (2003). Bi-directional immune-brain communication: implications for understanding stress, pain, and cognition. Brain Behav Immun 17: 69-85.

Martin SA, DeMuth TM, Miller KN, Pugh TD, Polewski MA, Colman RJ et al (2016). Regional metabolic heterogeneity of the hippocampus is nonuniformly impacted by age and caloric restriction. Aging Cell 15: 100-110.

McKim DB, Niraula A, Tarr AJ, Wohleb ES, Sheridan JF (2016). Neuroinflammatory Dynamics Underlie Memory Impairments after Repeated Social Defeat. J Neurosci 36: 2590-2604.

Miller AH, Maletic V, Raison CL (2009). Inflammation and its discontents: the role of cytokines in the pathophysiology of major depression. Biol Psychiatry 65: 732-741.

Miller KR, Streit WJ (2007). The effects of aging, injury and disease on microglial function: a case for cellular senescence. Neuron Glia Biol 3: 245-253.

Mitchell SJ, Scheibye-Knudsen M, Longo DL, de Cabo R (2015). Animal models of aging research: implications for human aging and age-related diseases. Annu Rev Anim Biosci 3: 283-303.

Moller JT, Cluitmans P, Rasmussen LS, Houx P, Rasmussen H, Canet J et al (1998). Long-term postoperative cognitive dysfunction in the elderly ISPOCD1 study. ISPOCD investigators. International Study of Post-Operative Cognitive Dysfunction. Lancet 351: 857-861.

Mosher Kl, Wyss-Coray T (2014). Microglial dysfunction in brain aging and Alzheimer's disease. Biochem Pharmacol 88: 594-604.

Mouton PR, Long JM, Lei DL, Howard V, Jucker M, Calhoun ME et al (2002). Age and gender effects on microglia and astrocyte numbers in brains of mice. Brain Res 956: 30-35. 
Munhoz CD, Lepsch LB, Kawamoto EM, Malta MB, Lima Lde S, Avellar MC et al (2006). Chronic unpredictable stress exacerbates lipopolysaccharide-induced activation of nuclear factor-kappaB in the frontal cortex and hippocampus via glucocorticoid secretion. J Neurosci 26: 3813-3820.

Murray CA, Lynch MA (1998). Evidence that increased hippocampal expression of the cytokine interleukin-1 beta is a common trigger for age- and stress-induced impairments in long-term potentiation. J Neurosci 18: 2974-2981.

Nimmerjahn A, Kirchhoff F, Helmchen F (2005). Resting microglial cells are highly dynamic surveillants of brain parenchyma in vivo. Science 308: 1314-1318.

Njie EG, Boelen E, Stassen FR, Steinbusch HW, Borchelt DR, Streit WJ (2012). Ex vivo cultures of microglia from young and aged rodent brain reveal age-related changes in microglial function. Neurobiol Aging 33: 195.e191-195.e112.

Norden DM, Fenn AM, Dugan A, Godbout JP (2014). TGFbeta produced by IL-10 redirected astrocytes attenuates microglial activation. Glia 62: 881-895.

Norden DM, Godbout JP (2013). Review: microglia of the aged brain: primed to be activated and resistant to regulation. Neuropathol Appl Neurobio/ 39: 19-34.

Norden DM, Trojanowski PJ, Walker FR, Godbout JP (2016). Insensitivity of astrocytes to interleukin 10 signaling following peripheral immune challenge results in prolonged microglial activation in the aged brain. Neurobiol Aging 44: 22-41.

Padgett DA, MacCallum RC, Sheridan JF (1998). Stress exacerbates age-related decrements in the immune response to an experimental influenza viral infection. J Gerontol A Biol Sci Med Sci 53: B347-B353.

Paolicelli RC, Bolasco G, Pagani F, Maggi L, Scianni M, Panzanelli P et al (2011). Synaptic pruning by microglia is necessary for normal brain development. Science 333: 1456-1458.

Parkhurst CN, Yang G, Ninan I, Savas JN, Yates JR 3rd, Lafaille JJ et al (2013). Microglia promote learning-dependent synapse formation through brain-derived neurotrophic factor. Cell 155: 1596-1609.

Patel SA, Chaudhari A, Gupta R, Velingkaar N, Kondratov RV (2015). Circadian clocks govern calorie restriction-mediated life span extension through BMAL1and IGF-1-dependent mechanisms. Faseb J 30: 1634-1642.

Perry VH, Holmes C (2014). Microglial priming in neurodegenerative disease. Nat Rev Neurol 10: 217-224.

Pfefferbaum A, Rohlfing T, Rosenbloom MJ, Chu W, Colrain IM, Sullivan EV (2013). Variation in longitudinal trajectories of regional brain volumes of healthy men and women (ages 10 to 85 years) measured with atlas-based parcellation of MRI. Neuroimage 65: 176-193.

Prehn K, Jumpertz von Schwartzenberg R, Mai K, Zeitz U, Witte AV, Hampel D et al (2016). Caloric restriction in older adults-differential effects of weight loss and reduced weight on brain structure and function. Cereb Cortex. (e-pub ahead of print).

Primiani CT, Ryan VH, Rao JS, Cam MC, Ahn K, Modi HR et al (2014). Coordinated gene expression of neuroinflammatory and cell signaling markers in dorsolateral prefrontal cortex during human brain development and aging. PLoS One 9: e110972.

Puntener U, Booth SG, Perry VH, Teeling JL (2012). Long-term impact of systemic bacterial infection on the cerebral vasculature and microglia. J Neuroinflammation 9: 146.

Raison CL, Rutherford RE, Woolwine BJ, Shuo C, Schettler P, Drake DF et al (2013). A randomized controlled trial of the tumor necrosis factor antagonist infliximab for treatment-resistant depression: the role of baseline inflammatory biomarkers. JAMA Psychiatry 70: 31-41.

Ramirez K, Niraula A, Sheridan JF (2016). GABAergic modulation with classical benzodiazepines prevent stress-induced neuro-immune dysregulation and behavioral alterations. Brain Behav Immun 51: 154-168.

Ramirez K, Shea DT, McKim DB, Reader BF, Sheridan JF (2015). Imipramine attenuates neuroinflammatory signaling and reverses stress-induced social avoidance. Brain Behav Immun 46: 212-220.

Richardson A, Austad SN, Ikeno Y, Unnikrishnan A, McCarter RJ (2015). Significant life extension by ten percent dietary restriction. Ann NY Acad Sci. 1363: 11-17.

Rizzo G, Veronese M, Tonietto M, Zanotti-Fregonara P, Turkheimer FE, Bertoldo A (2014). Kinetic modeling without accounting for the vascular component impairs the quantification of [(11)C]PBR28 brain PET data. J Cereb Blood Flow Metab 34: 1060-1069.

Ronnlund M, Nyberg L, Backman L, Nilsson LG (2005). Stability, growth, and decline in adult life span development of declarative memory: cross-sectional and longitudinal data from a population-based study. Psychol Aging 20: 3-18.

Roubenoff R, Harris TB, Abad LW, Wilson PW, Dallal GE, Dinarello CA (1998). Monocyte cytokine production in an elderly population: effect of age and inflammation. J Gerontol A Biol Sci Med Sci 53: M20-M26.

Rueger MA, Keuters MH, Walberer M, Braun R, Klein R, Sparing R et al (2012). Multi-session transcranial direct current stimulation (tDCS) elicits inflammatory and regenerative processes in the rat brain. PLoS One 7: e43776.
Rupprecht R, Papadopoulos V, Rammes G, Baghai TC, Fan J, Akula N et al (2010). Translocator protein (18 kDa) (TSPO) as a therapeutic target for neurological and psychiatric disorders. Nat Rev Drug Discov 9: 971-988.

Sack I, Beierbach B, Wuerfel J, Klatt D, Hamhaber U, Papazoglou S et al (2009). The impact of aging and gender on brain viscoelasticity. Neuroimage 46: 652-657.

Sapolsky RM (1992). Do glucocorticoid concentrations rise with age in the rat? Neurobiol Aging 13: 171-174.

Scholz R, Caramoy A, Bhuckory MB, Rashid K, Chen M, Xu H et al (2015). Targeting translocator protein $(18 \mathrm{kDa})(\mathrm{TSPO})$ dampens pro-inflammatory microglia reactivity in the retina and protects from degeneration. $J$ Neuroinflammation 12 : 201.

Schuitemaker A, van der Doef TF, Boellaard R, van der Flier WM, Yaqub M, Windhorst AD et al (2012). Microglial activation in healthy aging. Neurobiol Aging 33: 1067-1072.

Seals DR, Melov S (2014). Translational geroscience: emphasizing function to achieve optimal longevity. Aging (Albany NY) 6: 718-730.

Sierra A, Gottfried-Blackmore AC, McEwen BS, Bulloch K (2007). Microglia derived from aging mice exhibit an altered inflammatory profile. Glia 55: 412-424.

Singh-Manoux A, Kivimaki M, Glymour MM, Elbaz A, Berr C, Ebmeier KP et al (2012). Timing of onset of cognitive decline: results from Whitehall II prospective cohort study. BMJ 344: d7622.

Sinha M, Jang YC, Oh J, Khong D, Wu EY, Manohar R et al (2014). Restoring systemic GDF11 levels reverses age-related dysfunction in mouse skeletal muscle. Science 344: 649-652.

Smith DH, Johnson VE, Stewart W (2013). Chronic neuropathologies of single and repetitive TBl: substrates of dementia? Nat Rev Neurol 9: 211-221.

Spalding KL, Bergmann O, Alkass K, Bernard S, Salehpour M, Huttner HB et al (2013). Dynamics of hippocampal neurogenesis in adult humans. Cell 153: 1219-1227.

Storsve AB, Fjell AM, Tamnes CK, Westlye LT, Overbye K, Aasland HW et al (2014). Differential longitudinal changes in cortical thickness, surface area and volume across the adult life span: regions of accelerating and decelerating change. J Neurosci 34: 8488-8498.

Streit WJ, Miller KR, Lopes KO, Njie E (2008). Microglial degeneration in the aging brain-bad news for neurons? Front Biosci 13: 3423-3438.

Streit WJ, Sammons NW, Kuhns AJ, Sparks DL (2004). Dystrophic microglia in the aging human brain. Glia 45: 208-212.

Streit WJ, Walter SA, Pennell NA (1999). Reactive microgliosis. Prog Neurobiol 57: 563-581.

Streit WJ, Xue QS (2010). The brain's aging immune system. Aging Dis 1: 254-261.

Sundberg JP, Berndt A, Sundberg BA, Silva KA, Kennedy V, Bronson R et al (2011). The mouse as a model for understanding chronic diseases of aging: the histopathologic basis of aging in inbred mice. Pathobiol Aging Age Relat Dis 1; http://www.pathobiologyofaging.net/index.php/pba/article/view/7179.

Suridjan I, Rusjan PM, Voineskos AN, Selvanathan T, Setiawan E, Strafella AP et al (2014). Neuroinflammation in healthy aging: a PET study using a novel Translocator Protein 18kDa (TSPO) radioligand, [(18)F]-FEPPA. Neuroimage 84: 868-875.

Swindell WR (2009). Genes and gene expression modules associated with caloric restriction and aging in the laboratory mouse. BMC Genomics 10: 585.

Tan ZS, Beiser AS, Vasan RS, Roubenoff R, Dinarello CA, Harris TB et al (2007). Inflammatory markers and the risk of Alzheimer disease: the Framingham Study. Neurology 68: 1902-1908.

Tegeler C, O'Sullivan JL, Bucholtz N, Goldeck D, Pawelec G, Steinhagen-Thiessen E et al (2016). The inflammatory markers CRP, IL-6, and IL-10 are associated with cognitive function-data from the Berlin Aging Study II. Neurobiol Aging 38: 112-117.

Torres-Platas SG, Cruceanu C, Chen GG, Turecki G, Mechawar N (2014). Evidence for increased microglial priming and macrophage recruitment in the dorsal anterior cingulate white matter of depressed suicides. Brain Behav Immun 42: 50-59.

Townsend J, Adamo M, Haist F (2006). Changing channels: an fMRI study of aging and cross-modal attention shifts. Neuroimage 31: 1682-1692.

Trang T, Beggs S, Wan X, Salter MW (2009). P2X4-receptor-mediated synthesis and release of brain-derived neurotrophic factor in microglia is dependent on calcium and p38-mitogen-activated protein kinase activation. J Neurosci 29: 3518-3528.

Tremblay ME, Zettel ML, Ison JR, Allen PD, Majewska AK (2012). Effects of aging and sensory loss on glial cells in mouse visual and auditory cortices. Glia 60: 541-558.

Trepanowski JF, Canale RE, Marshall KE, Kabir MM, Bloomer RJ (2011). Impact of caloric and dietary restriction regimens on markers of health and longevity in humans and animals: a summary of available findings. Nutr $\mathrm{J}$ 10: 107.

Turkheimer FE, Rizzo G, Bloomfield PS, Howes O, Zanotti-Fregonara P, Bertoldo A et al (2015). The methodology of TSPO imaging with positron emission tomography. Biochem Soc Trans 43: 586-592. 
Tynan RJ, Naicker S, Hinwood M, Nalivaiko E, Buller KM, Pow DV et al (2010). Chronic stress alters the density and morphology of microglia in a subset of stress-responsive brain regions. Brain Behav Immun 24: 1058-1068.

van Praag H, Shubert T, Zhao C, Gage FH (2005). Exercise enhances learning and hippocampal neurogenesis in aged mice. J Neurosci 25: 8680-8685.

VanGuilder HD, Bixler GV, Brucklacher RM, Farley JA, Yan H, Warrington JP et al (2011). Concurrent hippocampal induction of MHC II pathway components and glial activation with advanced aging is not correlated with cognitive impairment. J Neuroinflammation 8: 138.

Varadhan R, Yao W, Matteini A, Beamer BA, Xue QL, Yang H et al (2014). Simple biologically informed inflammatory index of two serum cytokines predicts 10 year all-cause mortality in older adults. J Gerontol A Biol Sci Med Sci 69: 165-173.

Vaughan DW, Peters A (1974). Neuroglial cells in the cerebral cortex of rats from young adulthood to old age: an electron microscope study. J Neurocytol 3: 405-429.

Villeda SA, Luo J, Mosher KI, Zou B, Britschgi M, Bieri G et al (2011). The ageing systemic milieu negatively regulates neurogenesis and cognitive function. Nature 477: 90-94.

Villeda SA, Plambeck KE, Middeldorp J, Castellano JM, Mosher KI, Luo J (2014). Young blood reverses age-related impairments in cognitive function and synaptic plasticity in mice. Nat Med 20: 659-663.

Voorhees JL, Tarr AJ, Wohleb ES, Godbout JP, Mo X, Sheridan JF et al (2013). Prolonged restraint stress increases IL-6, reduces IL-10, and causes persistent depressive-like behavior that is reversed by recombinant IL-10. PLoS One 8: e58488.

Vukovic J, Colditz MJ, Blackmore DG, Ruitenberg MJ, Bartlett PF (2012). Microglia modulate hippocampal neural precursor activity in response to exercise and aging. J Neurosci 32: 6435-6443.

West MJ, Coleman PD, Flood DG, Troncoso JC (1994). Differences in the pattern of hippocampal neuronal loss in normal ageing and Alzheimer's disease. Lancet 344: 769-772.

Whooley MA, Caska CM, Hendrickson BE, Rourke MA, Ho J, Ali S (2007). Depression and inflammation in patients with coronary heart disease: findings from the Heart and Soul Study. Biol Psychiatry 62: 314-320.

Willette AA, Bendlin BB, McLaren DG, Canu E, Kastman EK, Kosmatka KJ et al (2010). Age-related changes in neural volume and microstructure associated with interleukin- 6 are ameliorated by a calorie-restricted diet in old rhesus monkeys. Neuroimage 51: 987-994.
Willette AA, Coe CL, Colman RJ, Bendlin BB, Kastman EK, Field AS et al (2012). Calorie restriction reduces psychological stress reactivity and its association with brain volume and microstructure in aged rhesus monkeys. Psychoneuroendocrinology 37: 903-916.

Witte AV, Fobker M, Gellner R, Knecht S, Floel A (2009). Caloric restriction improves memory in elderly humans. Proc Natl Acad Sci USA 106: 1255-1260.

Wohleb ES, Fenn AM, Pacenta AM, Powell ND, Sheridan JF, Godbout JP (2012). Peripheral innate immune challenge exaggerated microglia activation, increased the number of inflammatory CNS macrophages, and prolonged social withdrawal in socially defeated mice. Psychoneuroendocrinology 37: 1491-1505.

Wohleb ES, Hanke ML, Corona AW, Powell ND, Stiner LM, Bailey MT et al (2011). $\beta$-Adrenergic receptor antagonism prevents anxiety-like behavior and microglial reactivity induced by repeated social defeat. J Neurosci 31: 6277-6288.

Wohleb ES, McKim DB, Shea DT, Powell ND, Tarr AJ, Sheridan JF et al (2014). Re-establishment of anxiety in stress-sensitized mice is caused by monocyte trafficking from the spleen to the brain. Biol Psychiatry 75: 970-981.

Wynne AM, Henry CJ, Huang Y, Cleland A, Godbout JP (2010). Protracted downregulation of CX3CR1 on microglia of aged mice after lipopolysaccharide challenge. Brain Behav Immun 24: 1190-1201.

Yau JL, Wheelan N, Noble J, Walker BR, Webster SP, Kenyon CJ et al (2015). Intrahippocampal glucocorticoids generated by 11 beta-HSD1 affect memory in aged mice. Neurobiol Aging 36: 334-343.

Yirmiya R, Rimmerman N, Reshef R (2015). Depression as a microglial disease. Trends Neurosci 38: 637-658.

Youm YH, Horvath TL, Mangelsdorf DJ, Kliewer SA, Dixit VD (2016). Prolongevity hormone FGF21 protects against immune senescence by delaying age-related thymic involution. Proc Natl Acad Sci U S A 113: 1026-1031.

Zannas AS, Arloth J, Carrillo-Roa T, lurato S, Roh S, Ressler KJ et al (2015). Lifetime stress accelerates epigenetic aging in an urban, African American cohort: relevance of glucocorticoid signaling. Genome Biol 16: 266.

Zhan Y, Paolicelli RC, Sforazzini F, Weinhard L, Bolasco G, Pagani F et al (2014). Deficient neuron-microglia signaling results in impaired functional brain connectivity and social behavior. Nat Neurosci 17: 400-406.

Zhang H, Sachdev PS, Wen W, Crawford JD, Brodaty H, Baune BT et al (2016). The relationship between inflammatory markers and voxel-based gray matter volumes in nondemented older adults. Neurobiol Aging 37: 138-146. 